\title{
Minireview
}

\section{Vitamin E succinate and cancer treatment: a vitamin E prototype for selective antitumour activity}

\author{
J Neuzil*,1,2 \\ 'School of Health Sciences, Griffith University, Southport 9726, Queensland, Australia; ${ }^{2}$ Department of Pathology II, University Hospital, Linkoping, \\ Sweden
}

Great hope has been given to micronutrients as anticancer agents, since they present natural compounds with beneficial effects for normal cells and tissues. One of these is vitamin E (VE), an antioxidant and an essential component of biological membranes and circulating lipoproteins. In spite of a number of epidemiological and intervention studies, little or no correlation between VE intake and incidence of cancer has been found. Recent reports have identified a redox-silent analogue of VE, $\boldsymbol{\alpha}$-tocopheryl succinate $(\boldsymbol{\alpha}$ TOS), as a potent anticancer agent with a unique structure and pharmacokinetics in vivo. $\alpha$-TOS is highly selective for malignant cells, inducing them into apoptotic death largely via the mitochondrial route. The molecule of $\alpha$-TOS may be modified so that analogues with higher activity are generated. Finally, $\alpha$-TOS and similar agents are metabolised to VE, thereby yielding a compound with a secondary beneficial activity. Thus, $\alpha$-TOS epitomises a group of novel compounds that hold substantial promise as future anticancer drugs. The reasons for this optimistic notion are discussed in the following paragraphs.

British Journal of Cancer (2003) 89, I822 - | 826. doi:I0.I038/sj.bjc.660I360 www.bjcancer.com

(c) 2003 Cancer Research UK

Keywords: $\alpha$-tocopheryl succinate; vitamin E analogues; apoptosis; neoplastic disease; pharmacokinetics

\section{VITAMIN E (VE) IS A POOR ANTICANCER AGENT}

Numerous epidemiological and intervention studies tested the possibility that VE suppresses cancer (see e.g. Albanes et al, 1996, 2000; Heinonen et al, 1998; Heart Protection Study Collaborative Group, 2002). The idea has been attractive, as VE is a micronutrient with high antioxidant activity. To a certain degree, the level of VE can be manipulated by dietary supplementation. As the hepatic system prevents both VE hyper- and hypovitaminosis, maintaining the circulating/tissue levels of VE within a narrow margin, pathologies associated with too much or too little VE, are rare. Therefore, it is apparent that diseases linked to VE deficiency will only occur in association with infrequent syndromes of impairment of VE intake and its maintenance, such as abetalipoproteinaemia or the familial isolated VE deficiency syndrome. On the other hand, given the relatively narrow margin between minimal and maximal VE levels in circulating lipoproteins and in tissues, there is only a limited scope for VE manipulation by intervention therapy. Hence, it is not surprising that little or no association between disease incidence, including neoplasia, and VE intake has been repeatedly observed (Albanes et al, 1996, 2000; Heart Protection Study Collaborative Group, 2002). Attempts to find a correlation between VE supplementation and pathology may have failed as, following VE ingestion, its level raises only transiently, the 'excess' VE being efficiently removed from the body by the hepatic system armed with the saturable $\alpha$-tocopherol $(\alpha-\mathrm{TOH})$ transfer protein (Brigelius-Flohe et al, 2002).

*Correspondence: Dr J Neuzil; E-mail: j.neuzil@griffith.edu.au Received 16 May 2003; revised 27 August 2003; accepted 12 September 2003

\section{$\alpha$-TOCOPHERYL SUCCINATE ( $\alpha$-TOS) IS AN ANTICANCER VE ANALOGUE DUE TO ITS APOPTOGENIC ACTIVITY}

Probably, the main reason why VE as such exerts little or no anticancer effect may be due to its biological activity, since it is a redox-active substance, which does not cause, unlike many anticancer agents, apoptosis of malignant cells (Neuzil et al, 1999). This premise, however, has been found for semisynthetic analogues of VE, as documented in a number of recent reports for $\alpha$-TOS (Fariss et al, 1994; Neuzil et al, 1999; Pussinen et al, 2000; Neuzil et al, 2001a-c; Yu et al, 2001). The mechanism by which $\alpha$ TOS kills cancer cells is not completely understood. It has been shown that this occurs by inducing apoptosis in malignant cells primarily by mitochondrial destabilisation (Alleva et al, 2001; Kogure et al, 2001; Neuzil et al, 2001c; Weber et al, 2003), a process amplified by the modulation of signalling pathways (Qian et al, 1997; Neuzil et al, 2001c; Yu et al, 2001). Mitochondrial destabilisation is caused, most likely, by the detergent-like activity of $\alpha$-TOS (Neuzil et al, 2002). That is, $\alpha$-TOS comprises a hydrophobic phytyl chain (hydrophobic domain) and the chargeable succinyl group (functional domain), separated by the bulky tocopheryl moiety (signalling domain) (Neuzil, 2002). It is possible that $\alpha$-TOS-induced apoptosis also involves lysosomal destabilisation by the agent, an action running parallel to and/or amplifying mitochondrial disruption (Neuzil et al, 2002). $\alpha$-TOS may signal along several pathways. It has been shown that, due to its $\alpha$ tocopheryl moiety, the agent activates protein phosphatase-2A that, in turn, inhibits protein kinase C (PKC). This leads to hypophosphorylation of the antiapoptotic protein bcl-2, with ensuing mitochondrial labilisation (Neuzil et al, 2001c). This pathway itself does not cause apoptosis by the VE analogues, but 
rather amplifies the succinyl moiety-mediated destabilisation of mitochondria, since $\beta$-, $\gamma$ - and $\delta$-TOS lacking the PKC inhibitory activity are less apoptogenic than the $\alpha$-analogue (Neuzil et al, 2001c; Birringer et al, 2003). Other pathways that are likely implicated in apoptosis induced by $\alpha$-TOS include deregulation of the c-jun/AP-1 (Qian et al, 1997) and the TGF- $\beta$ pathway (Turley et al, 1995), as well as inhibition of the cell cycle transition (Turley et al, 1997a, b).

The strong apoptogenic activity of $\alpha$-TOS translates to its anticancer efficacy, as shown in preclinical models. Malafa and coworkers have demonstrated the inhibition of breast cancer in a mouse model (Malafa and Neitzel, 2000), as well as suppression of melanomas (Malafa et al, 2002a) and colon cancer metastasis (Barnett et al, 2002). We have shown that the VE analogue suppressed colon cancer in an athymic mouse model, and its antineoplastic effect was much higher than that of $\alpha$-TOH, which exerted only minor, nonsignificant cancer suppression (Weber et al, 2002). The great superiority of $\alpha$-TOS over $\alpha$-TOH in cancer inhibition is due to the fact that, while both agents inhibit proliferation of malignant cells in the xenografts, only $\alpha$-TOS causes their apoptosis (Weber et al, 2002) (Figure 1A). Another possible mode of antineoplastic activity of VE succinate is that it appears to be antiangiogenic (Malafa et al, 2002b). This notion follows also from findings that $\alpha$-TOS causes apoptosis of proliferating, but not growth-arrested endothelial cells (Neuzil et al, 2002), and inhibits the expression of angiogenic cytokines, such as VEGF (Malafa and Neitzel, 2000). We have recently observed suppression of blood vessel sprouting by $\alpha$-TOS in a mouse model of neonatal retinal neovascularisation (Neuzil et al, unpublished).

\section{PROAPOPTOTIC/ANTINEOPLASTIC ACTIVITY OF VE ANALOGUES IS STRUCTURE-DEPENDENT}

The reason why $\alpha$-TOS is proapoptotic while $\alpha$-TOH does not possess this activity (in fact, $\alpha-\mathrm{TOH}$ is antiapoptotic) has been investigated in considerable detail over the last few years. Importantly, Fariss et al (1994) showed that the cell-killing activity of $\alpha$-TOS requires an intact molecule of the agent. They reported that the ester, which can be hydrolysed by some cells to free VE, has identical activity as its ether counterpart that is not hydrolysable. We have explored in more detail the structurefunction relationship of these agents and found several interesting features (Birringer et al, 2003). Firstly, the presence of the phytyl group was essential for the activity, since the succinyl ester of Trolox was inactive. This can be explained by the fact that such a molecule is highly water soluble, therefore does not associate with lipid membranes. As mentioned earlier, lowering the number of methyl substituents on the tocopheryl moiety decreased the proapoptotic efficacy. Replacement of the succinyl group by an uncharged group, for example acetate, or its methylation, obliterated the proapoptotic activity. On the other hand, esterification of $\alpha-\mathrm{TOH}$ with other dicarboxylic acids modulated the apoptogenic activity as follows: esters with higher number of carbons had lower activity than $\alpha$-TOS, while esterification with unsaturated dicarboxylic acids, such as maleyl acid, highly enhanced the activity. Thus, $\alpha$-tocopheryl maleate $(\alpha$-TOM) is the most apoptogenic VE analogue tested to date (Birringer et al, 2003).

The unique structural features of agents like $\alpha$-TOS probably make them selective for malignant cells (Neuzil et al, 2001b). While speculative at present, it is possible that the surprisingly high toxicity of $\alpha$-TOS towards cancer cells and tissues is due to their persistence in such cells in the original form, while normal cells, including fibroblasts (Roberg et al, 1999), cardiac myocytes (Roberg and Ollinger, 1998), hepatocytes (Tirmenstein et al, 1999) and intestinal epithelial cells (Borel et al, 2001), are all
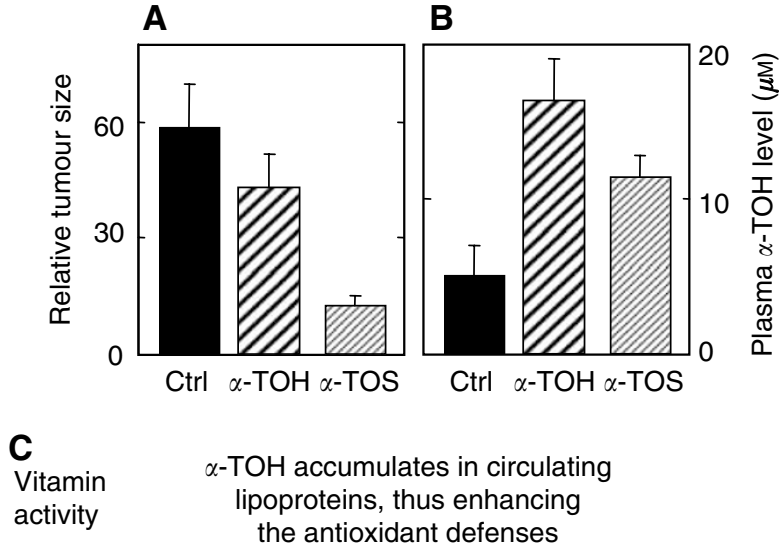

activity the antioxidant defenses

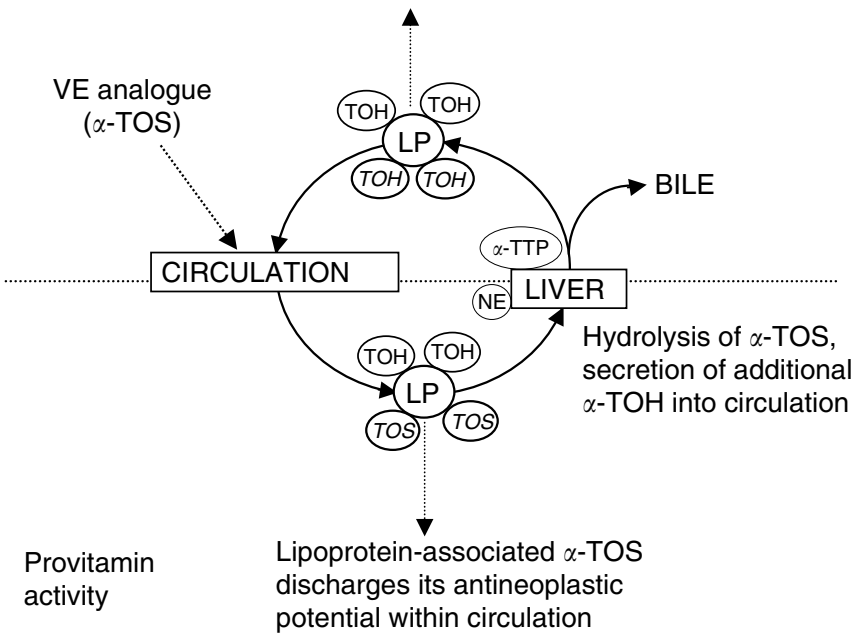

Figure I $\alpha$-TOS inhibits colon cancer $(\mathbf{A})$, and is converted to the redox-active $\alpha$-TOH (B) (adapted from Weber et al, 2002). Nude mice with colon cancer xenografts were treated with the vehicle (control), $\alpha$ $\mathrm{TOH}$ or $\alpha$-TOS, by intraperitoneal injection of $100 \mathrm{nmol}$ of the drug, every second day for 10 days. In the end, the tumour size was estimated $(\mathbf{A})$ and the mouse plasma was analysed for the level of $\alpha-\mathrm{TOH}(\mathbf{B})$. (C) Bases of the hypothesis are presented in this communication. After reaching the circulation, a VE analogue (epitomised in our studies by $\alpha$-TOS) binds to circulating lipoproteins (LP), which carry it to the microvasculature, where it kills cancer cells (this is the 'provitamin E effect'). Lipoproteins with bound $\alpha$-TOS are cleared in the liver, where nonspecific esterase (NE) very efficiently cleaves it into $\alpha-\mathrm{TOH}$. The newly generated $\alpha-\mathrm{TOH}$ is in part excreted in the bile, in part bound to the saturable $\alpha$-tocopheryl-transfer protein $(\alpha$-TTP), which inserts it into nascent very low-density lipoprotein. In this way, the provitamin $E$ is converted to VE, which increases the antioxidant defences and acts as an immunosuppressive agent.

capable of its hydrolysis to $\alpha$-TOH. On the other hand, malignant cells, such as the human $\mathrm{T}$ lymphoma, malignant mesothelioma and colon cancer cells exert only a very low hydrolytic capacity towards $\alpha$-TOS (Neuzil et al, unpublished). Another reason for the selectivity of $\alpha$-TOS may result from its physicochemical properties. The VE analogue is a weak acid with a low $\mathrm{p} K_{\mathrm{a}}$ value. Therefore, at the neutral $\mathrm{pH}$ of normal tissue interstitium, majority of $\alpha$-TOS exists in the charged, deprotonated state. Since there are no known transporters of $\alpha$-TOS, it can be expected that it will cross the plasma membrane at a low rate. On the other hand, the acidic $\mathrm{pH}$ of the tumour interstitium causes protonation of a substantial portion of the total $\alpha$-TOS, facilitating its free diffusion into the cell. In favour of this hypothesis, lowering the $\mathrm{pH}$ of the cell culture medium enhanced the killing of cancer cells by $\alpha$-TOS, but not by $\gamma$-tocotrienol, an apoptogenic VE analogue that cannot be deprotonated (Neuzil et al, 2002). This is consistent with the 
idea that inducers of apoptosis that are weak acids may be selective anticancer agents due to their preferential uptake by tumour tissue cells (Gerweck et al, 1999; Kozin et al, 2001).

It is therefore possible to modify the structure of VE analogues so that agents with higher proapoptotic activity and selectivity for malignant cells are generated. Thus, this group of compounds provides a unique opportunity for further structure-activity studies.

\section{VE ANALOGUES AS ADJUVANTS FOR CANCER IMMUNOTHERAPY}

A commonly used practice in tumour treatment is to combine several anticancer agents with different modes of action. The reasons for this approach are both maximising the apoptotic potential of the cell, overcoming resistance to one of the agents by utilising complementing proapoptotic pathways and lowering the doses of the individual drugs to suppress the potential secondary deleterious effects of the treatment. From this point of view, $\alpha$-TOS has shown substantial promise.

There are several reports documenting that the VE analogue potentiates cancer cells killing by the immunological apoptogen Fas, viz by mobilising the Fas receptor from the cytosol to the plasma membrane; this has been shown for both prostate and breast cancer cells (Turley et al, 1997; Yu et al, 1999). These findings suggest that $\alpha$-TOS has the propensity to boost the immune system to enhance cancer surveillance. While the Fas ligand itself is highly cytotoxic, the TNF-related apoptosisinducing ligand (TRAIL) is selective for cancer cells (Bonavida et al, 1999). Therefore, the reports that $\alpha$-TOS can potentiate cancer cells to killing by TRAIL may be of pharmacological importance. This has been shown for both colon cancer (Weber et al, 2002) and mesothelioma cells (Neuzil et al, unpublished) as well as for $\mathrm{T}$ lymphoma cells (Dalen and Neuzil, 2003). One mechanism by which $\alpha$-TOS sensitises cells to killing by TRAIL is that the two agents use different pathways of apoptotic signalling, that is, $\alpha$-TOS activates the distant, mitochondrial pathway, while TRAIL acts through the proximal, receptor-mediated route (Weber et al, 2002). Moreover, the in vitro cooperative killing of colon cancer cells by the two agents has also been reported for the suppression of colon cancer in a preclinical model (Weber et al, 2002). Another possible mechanism of synergism and/or cooperation between TRAIL and $\alpha$-TOS is the inhibition of activation of the nuclear factor- $\kappa \mathrm{B}(\mathrm{NF} \kappa \mathrm{B})$. This transcriptional factor controls the expression of a number of prosurvival genes, and is activated in some cancer cells due to TRAIL crosslinking of one or more of its cognate receptors (Degli-Esposti et al, 1997; Bernard et al, 2001). $\alpha$-TOS has been shown to suppress the activation of NF $\kappa \mathrm{B}$ (Suzuki and Packer, 1993; Erl et al, 1997), and we have shown that this may be due to the induction of proapoptotic signalling leading to caspase- 3 activation that, in turn, cleaves the NF $\kappa$ B subunit 065 (Neuzil et al, 2001a). A recent finding revealing that the suppression of NFKB activation by $\alpha$-TOS, following exposure to TRAIL, sensitises $\mathrm{T}$ lymphoma cells to killing by the immunological apoptogen (Dalen and Neuzil, 2003), may be of pharmacological interest. Finally, $\alpha$-TOS can sensitise cancer cells by upregulation of the TRAIL death receptors, as in the TRAILresistant mesothelioma cells (Neuzil et al, unpublished).

\section{THE PROMISE OF CANCER THERAPY BY VE ANALOGUES IS BASED ON PRECLINICAL STUDIES}

Thus far, there have been very few studies on the anticancer effects of VE analogues in vivo. This is surprising, since the toxic effects of $\alpha$-TOS towards malignant cells have been known since the early 1980s (Prasad and Edwards-Prasad, 1982; Prasad et al, 2003). Probably, the strongest evidence suggesting the potential use of VE analogues in the treatment of humans with neoplastic disease comes from the laboratory of Malafa. They first showed that $\alpha$-TOS promoted beast cancer dormancy in an immunocompromised mouse (Malafa and Neitzel, 2000) and, later on, also melanoma dormancy (Malafa et al, 2002b); in both cases, inhibition of angiogenesis via suppression of VEGF signalling by $\alpha$-TOS was suggested as the underlying mechanism, pointing to an indirect effect of the VE analogue on cancer growth. The acute effect of $\alpha$ TOS has been shown by the same group for experimental melanoma (Malafa et al, 2002a) and colon cancer liver metastases (Barnett et al, 2002), and similar suppression of experimental melanomas has been observed by others (Kogure et al, 2003). In these experiments, the main mode of action of $\alpha$-TOS was ascribed to its apoptogenic effect on the cancer cells. We have reported a significant inhibition of colon cancer growth in immunocompromised mice treated with $\alpha$-TOS and its superiority to $\alpha$-TOH (Neuzil et al, 2001c; Weber et al, 2002), and have also shown its cooperativity in vivo with the immunological apoptogen TRAIL (Weber et al, 2002). Finally, our recent studies revealed that $\alpha$-TOS strongly enhances the survival of immunocompromised mice with experimental peritoneal mesothelioma, a thus far incurable type of human neoplastic disease (Neuzil et al, unpublished data).

Although these studies show a strong promise, there are certain drawbacks that need to be solved before $\alpha$-TOS and similar compounds its possible application to humans. These compounds are esters of VE, and as such, are fully hydrolysed during the intestinal uptake following oral administration. Therefore, intravenous application is required. This can be overcome by generating analogues where the ester bond is replaced by an ether bond (Fariss et al, 1994), since ethers are not subject to enzymatic hydrolysis. An ether VE analogue has been recently reported as being highly effective in suppressing mammary tumours and lung metastases in syngeneic mice (Lawson et al, 2003). While this approach makes it possible to administer VE analogues orally, it jeopardises the most intriguing feature of the analogues based on VE esters in that the ether compounds are not broken down to the free VE (see below). Notwithstanding, the ether analogues of VE make it possible to administer the drugs orally, which has a clear advantage over intravenous application of the ester compounds, and we and others are pursuing this option as well.

\section{PHARMACOKINETICS OF VE ESTERS - A NOVEL PROVITAMIN-TO-VITAMIN CONVERSION MODEL}

Perhaps, the most exciting aspect of the potential use of compounds like $\alpha$-TOS, a pro-VE, follows from its pharmacokinetics. After infusion into the circulatory system, the VE analogue associates with circulating lipoproteins (Kayden and Traber, 1993; Pussinen et al, 2000). This carrier delivers it to the microvasculature of the tumour. Since there is a constant exchange of hydrophobic molecules between lipoproteins and the peripheral tissue, $\alpha$-TOS can traverse to malignant cells, where it induces apoptosis (Neuzil, 2002). Due to rapid turnover of lipoproteins (Traber et al, 1994), $\alpha$-TOS is eventually cleared in the liver. Hepatocytes have a high activity of nonspecific esterases that cleave the VE ester to $\alpha$-TOH. Further, during processing of lipoproteins in the liver cells, the natural stereoisomer of $\alpha$-TOH associates with the highly specific $\alpha$-TOH-binding protein, which inserts this most active form of VE into nascent very low-density lipoprotein that is, in turn, resecreted into circulation via the hepatic vein (Terasawa et al, 2000). In this way, following hydrolysis of $\alpha$-TOS, the circulation is enriched with VE. Therefore, the pro-VE, $\alpha$-TOS and similar compounds (Birringer et al, 2003) are converted to the redox-active VE with additional beneficial activity (Neuzil, 2002), including increased protection against oxidative stress and immunosuppressive activity (LiWeber et al, 2002). Moreover, several reports showed that $\alpha$-TOS 
protects cells like hepatocytes from secondary deleterious effects of toxic agents, including adriamycin (Dominguez-Rodriguez et al, 2001; Fariss et al, 2001).

Based on direct and circumstantial evidence and on theoretical considerations, a novel hypothesis is proposed explaining why VE is inefficient as an anticancer agent and why its analogues may be deemed as potent anticancer drugs (Figure 1B). According to this hypothesis, VE succinate and similar analogues (in general, esters of VE with a free carboxylic group) induce apoptosis selectively in cancer cells while VE itself is not apoptogenic. Due to multiple activities, including apoptosis induction and sensitisation of cancer cell killing by other agents, VE succinate and its analogues inhibit cancer growth. Following the anticancer activity discharge, the pro-VE is converted to the redox-active VE, part of which enters the circulation.

Therefore, it is imperative to test this hypothesis, as it is believed that VE analogues, epitomised by $\alpha$-TOS, represent an exciting group of novel anticancer agents of potential high pharmacological importance.

\section{ACKNOWLEDGEMENTS}

The author has been supported by grants from the Dust Diseases Board of Australia and the Queensland Cancer Fund.

\section{REFERENCES}

Albanes D, Heinonen OP, Taylor PR, Virtamo J, Edwards BK, Rautalahti M, Hartman AM, Palmgren J, Freedman LS, Haapakoski J, Barrett MJ, Pietinen P, Malila N, Tala E, Liippo K, Salomaa ER, Tangrea JA, Teppo L, Askin FB, Taskinen E, Erozan Y, Greenwald P, Huttunen JK (1996) Tocopherol and $\beta$-carotene supplements and lung cancer incidence in the $\alpha$-tocopherol, $\beta$-carotene cancer prevention study: effects of base-line characteristics and study compliance. J Natl Cancer Inst 88: 1560-1570

Albanes D, Malila N, Taylor PR, Huttunen JK, Virtamo J, Edwards BK, Rautalahti M, Hartman AM, Barrett MJ, Pietinen P, Hartman TJ, Sipponen P, Lewin K, Teerenhovi L, Hietanen P, Tangrea JA, Virtanen M, Heinonen OP (2000) Effects of supplemental $\alpha$-tocopherol and $\beta$ carotene on colorectal cancer: results from a controlled trial. Cancer Causes Control 11: 197-205

Alleva R, Tomasetti M, Andera L, Gellert N, Borghi B, Weber C, Murphy MP, Neuzil J (2001) Coenzyme Q blocks biochemical but not receptormediated apoptosis by increasing mitochondrial antioxidant protection. FEBS Lett 503: 46-50

Barnett KT, Fokum FD, Malafa MP (2002) Vitamin E succinate inhibits colon cancer liver metastases. J Surg Res 106: 292-298

Bernard D, Quatannens B, Vandenbunder B, Abbadie C (2001) Rel/NF- $\kappa$ B transcription factors protect against tumor necrosis factor (TNF)-related apoptosis-inducing ligand (TRAIL)-induced apoptosis by up-regulating the TRAIL decoy receptor DcR1. J Biol Chem 276: $27322-27328$

Birringer M, EyTina JH, Salvatore BA, Neuzil J (2003) Vitamin E analogues as inducers of apoptosis: structure-function relationship. Br J Cancer 88: $1948-1955$

Bonavida B, Ng CP, Jazirehi A, Schiller G, Mizutani Y (1999) Selectivity of TRAIL-mediated apoptosis of cancer cells and synergy with drugs: the trail to non-toxic cancer therapeutics (review). Int J Oncol 15: 793-802

Borel P, Pasquier B, Armand M, Tyssandier V, Grolier P, AlexandreGouabau MC, Andre M, Senft M, Peyrot J, Jaussan V, Lairon D, AzaisBraesco V (2001) Processing of vitamin A and $\mathrm{E}$ in the human gastrointestinal tract. Am J Physiol 280: G95-G103

Brigelius-Flohe R, Kelly FJ, Salonen JT, Neuzil J, Zingg JM, Azzi A (2002) The European perspective on vitamin E: current knowledge and future research. Am J Clin Nutr 76: 703-716

Dalen H, Neuzil J (2003) Tocopheryl succinate sensitises a T lymphoma cell line to TRAIL killing by suppressing NF- $\mathrm{\kappa B}$ activation. Br J Cancer 88: $153-158$

Degli-Esposti MA, Dougall WC, Smolak PJ, Waugh JY, Smith CA, Goodwin RG (1997) The novel receptor TRAIL-R4 induces NF- $\kappa$ B and protects against TRAIL-mediated apoptosis, yet retains an incomplete death domain. Immunity 7: 813-820

Dominguez-Rodriguez JR, Gomez-Contreras PC, Hernandez-Flores G, Lerma-Diaz JM, Carranco A, Cervantes-Munguia R, Orbach-Arbouys S, Bravo-Cuella A (2001) In vivo inhibition by antioxidants of adriamycininduced apoptosis in murine peritoneal macrophages. Anticancer Res 21: $1869-1872$

Erl W, Weber C, Wardemann C, Weber PC (1997) Tocopheryl succinate inhibits monocytic cell adhesion to endothelial cells by suppressing NF$\kappa B$ mobilization. Am J Physiol 273: H634-H640

Fariss MW, Fortuna MB, Everett CK, Smith JD, Trent DF, Djuric Z (1994) The selective antiproliferative effects of $\alpha$-tocopheryl hemisuccinate and cholesteryl hemisuccinate on murine leukemia cells result from the action of the intact compounds. Cancer Res 54: 3346-3351
Fariss MW, Nicholls-Grzemski FA, Tirmenstein MA, Zhang JG (2001) Enhanced antioxidant and cytoprotective abilities of vitamin E succinate is associated with a rapid uptake advantage in rat hepatocytes and mitochondria. Free Radical Biol Med 31: 530-541

Gerweck LE, Kozin SV, Stocks SJ (1999) The $\mathrm{pH}$ partition theory predicts the accumulation and toxicity of doxorubicin in normal and low-pHadapted cells. Br J Cancer 79: 838-842

Heart Protection Study Collaborative Group (2002) MRC/BHF Heart Protection Study of antioxidant vitamin supplementation in 20,536 highrisk individuals: a randomised placebo-controlled trial. Lancet 360: $23-33$ Heinonen OP, Albanes D, Virtamo J, Taylor PR, Huttunen JK, Hartman AM, Haapakoski J, Malila N, Rautalahti M, Ripatti S, Maenpaa H, Teerenhovi L, Koss L, Virolainen M, Edwards BK (1998) Prostate cancer and supplementation with $\alpha$-tocopherol and $\alpha$-carotene: incidence and mortality in a controlled trial. J Natl Cancer Inst 90: 440-446

Kayden HJ, Traber MG (1993) Absorption, lipoprotein transport, and regulation of plasma concentrations of vitamin $\mathrm{E}$ in humans. J Lipid Res 34: $343-358$

Kogure S, Manabe S, Hama S, Tokumura A, Fukuzawa K (2003) Potentiation of anti-cancer effect by intravenous administration of vesiculated $\alpha$-tocopheryl hemisuccinate on mouse melanoma in vivo. Cancer Lett 192: 19-24

Kogure K, Morita M, Nakashima S, Hama S, Tokumura A, Fukuzawa K (2001) Superoxide is responsible for apoptosis in rat vascular smooth muscle cells induced by $\alpha$-tocopheryl hemisuccinate. Biochim Biophys Acta 1528: $25-30$

Kozin SV, Shkarin P, Gerweck LE (2001) The cell transmembrane pH gradient in tumors enhances cytotoxicity of specific weak acid chemotherapeutics. Cancer Res 61: 4740-4743

Lawson KA, Anderson K, Menchaca M, Atkinson J, Sun L, Knight V, Gilbert BE, Conti C, Sanders BG, Kline K (2003) Novel vitamin E analogue decreases syngeneic mouse mammary tumor burden and reduces lung metastasis. Mol Cancer Ther 2: 437-444

Li-Weber M, Weigand MA, Giaisi M, Suss D, Treiber MK, Baumann S, Ritsou E, Breitkreutz R, Krammer PH (2002) Vitamin E inhibits CD95 ligand expression and protects $\mathrm{T}$ cells from activation-induced cell death. J Clin Invest 110: $681-690$

Malafa MP, Fokum FD, Mowlavi A, Abusief M, King M (2002a) Vitamin E inhibits melanoma growth in mice. Surgery 131: 85-91

Malafa MP, Fokum FD, Smith L, Louis A (2002b) Inhibition of angiogenesis and promotion of melanoma dormancy by vitamin E succinate. Ann Surg Oncol 9: $1023-1032$

Malafa MP, Neitzel LT (2000) Vitamin E succinate promotes breast cancer tumor dormancy. J Surg Res 93: $163-170$

Neuzil J (2002) Tocopheryl succinate epitomizes a compound with a shift in biological activity due to pro-vitamin-to-vitamin conversion. Biochem Biophys Res Commun 293: 1309-1313

Neuzil J, Schroder A, von Hundelshausen P, Zernecke A, Weber T, Gellert $\mathrm{N}$, Weber C (2001a) Inhibition of inflammatory endothelial responses by a pathway involving caspase activation and p65 cleavage. Biochemistry 40: $4686-4692$

Neuzil J, Svensson I, Weber T, Weber C, Brunk UT (1999) Tocopheryl succinate-induced apoptosis in Jurkat $\mathrm{T}$ cells involves caspase-3 activation, and both lysosomal and mitochondrial destabilisation. FEBS Lett 445: 295-300 
Neuzil J, Weber T, Gellert N, Weber C (2001b) Selective cancer cell killing by $\alpha$-tocopheryl succinate. Br J Cancer 84: 87-89

Neuzil J, Weber T, Schroder A, Lu M, Ostermann G, Gellert N, Mayne GC, Olejnicka B, Negre-Salvayre A, Sticha M, Coffey RJ, Weber C (2001c) Induction of cancer cell apoptosis by $\alpha$-tocopheryl succinate: molecular pathways and structural requirements. FASEB $J$ 15: $403-415$

Neuzil J, Zhao M, Ostermann G, Sticha M, Gellert N, Weber C, Eaton JW, Brunk UT (2002) Tocopheryl succinate, an agent with in vivo antitumour activity, induces apoptosis by causing lysosomal instability. Biochem J 362: 709-715

Prasad KN, Edwards-Prasad J (1982) Effects of tocopherol (vitamin E) acid succinate on morphological alterations and growth inhibition in melanoma cells in culture. Cancer Res 42: 550-555

Prasad KN, Kumar B, Yan XD, Hanson AJ, Cole WC (2003) Tocopheryl succinate, the most effective form of vitamin $\mathrm{E}$ for adjuvant cancer treatment: a review. J Am Coll Nutr 22: 108-117

Pussinen PJ, Lindner $\mathrm{H}$, Glatter $\mathrm{O}$, Reicher $\mathrm{H}$, Kostner $\mathrm{GM}$, Wintersperger A, Malle E, Sattler W (2000) Lipoprotein-associated $\alpha$ tocopheryl-succinate inhibits cell growth and induces apoptosis in human MCF-7 and HBL-100 breast cancer cells. Biochim Biophys Acta 1485: $129-144$

Qian M, Kralova J, Yu W, Bose HR, Dvorak M, Sanders BG, Kline K (1997) c-Jun involvement in vitamin E succinate induced apoptosis of reticuloendotheliosis virus transformed avian lymphoid cells. Oncogene 15: $223-230$

Roberg K, Johansson U, Ollinger K (1999) Lysosomal release of cathepsin D precedes relocation of cytochrome $c$ and loss of mitochondrial transmembrane potential during apoptosis induced by oxidative stress. Free Radical Biol Med 27: 1228-1237

Roberg K, Ollinger K (1998) Oxidative stress causes relocation of the lysosomal enzymecathepsin D with ensuing apoptosis in neonatal rat cardiomyocytes. Am J Pathol 152: 1151-1156

Suzuki YJ, Packer L (1993) Inhibition of NF-kappa B DNA binding activity by $\alpha$-tocopheryl succinate. Biochem Mol Biol Int 31: 693-700

Terasawa Y, Ladha Z, Leonard SW, Morrow JD, Newland D, Sanan D, Packer L, Traber MG, Farese RV (2000) Increased atherosclerosis in hyperlipidemic mice deficient in $\alpha$-tocopherol transfer protein and vitamin E. Proc Natl Acad Sci USA 297: 13830-13834
Tirmenstein MA, Ge X, Elkins CR, Fariss MW (1999) Administration of the tris salt of $\alpha$-tocopheryl hemisuccinate inactivates CYP2E1, enhances microsomal $\alpha$-tocopherol levels and protects against carbon tetrachloride-induced hepatotoxicity. Free Radical Biol Med 26: 825-835

Traber MG, Ramakrishnan R, Kayden HJ (1994) Human plasma vitamin E kinetics demonstrate rapid recycling of plasma RRR- $\alpha$-tocopherol. Proc Natl Acad Sci USA 91: 10005-10008

Turley JM, Funakoshi S, Ruscetti FW, Kasper J, Murphy WJ, Longo DL, Birchenall-Roberts MC (1995) Growth inhibition and apoptosis of RL human B lymphoma cells by vitamin E succinate and retinoic acid: role for transforming growth factor- $\beta$. Cell Growth Differ 6: 655-663

Turley JM, Fu T, Ruscetti FW, Mikovits JA, Bertolette III DC, BirchenallRoberts MC (1997a) Vitamin E succinate induces Fas-mediated apoptosis in estrogen receptor-negative human breast cancer cells. Cancer Res 57: $881-890$

Turley JM, Ruscetti FW, Kim SJ, Fu T, Gou FV, Birchenall-Roberts MC (1997b) Vitamin E succinate inhibits proliferation of BT-20 human breast cancer cells: increased binding of cyclin A negatively regulates E2F transactivation activity. Cancer Res 57: 2668-2675

Weber T, Dalen H, Andera L, Nègre-Salvayre A, Sticha M, Lloret A, Terman A, Higuchi M, Plasilova M, Zivny J, Gellert N, Weber C, Neuzil J (2003) Mitochondria play a central role in apoptosis induced by $\alpha$-tocopheryl succinate, an agent with anticancer activity: comparison with receptormediated pro-apoptotic signaling. Biochemistry 42: 4277-4291

Weber T, Lu M, Andera L, Lahm H, Gellert N, Fariss MW, Korinek V, Sattler W, Ucker DS, Terman A, Schroder A, Erl W, Brunk UT, Coffey RJ, Weber C, Neuzil J (2002) Vitamin E succinate is a potent novel antineoplastic agent with high selectivity and cooperativity with tumor necrosis factor-related apoptosis-inducing ligand (Apo2 ligand) in vivo. Clin Cancer Res 8: 863-869

Yu W, Israel K, Liao QY, Aldaz CM, Sanders BG, Kline K (1999) Vitamin E succinate induces Fas sensitivity in human breast cancer cells: role for Mr 43,000 Fas in VES-triggered apoptosis. Cancer Res 59: 953-961

Yu W, Liao QY, Hantash FM, Sanders BG, Kline K (2001) Activation of extracellular signal-regulated kinase and c-Jun- $\mathrm{NH}_{2}$-terminal kinase but not p38 mitogen-activated protein kinases is required for RRR- $\alpha$ tocopheryl succinate-induced apoptosis of human breast cancer cells. Cancer Res 61: 6569-6576 